$10-1-2020$

\title{
We Know Health Is Not Elective: Impacts of COVID-19.
}

David B. Nash

Thomas Jefferson University

Mark Angelo

Delaware Valley Accountable Care Organization

Esther J Nash

Consultant, Population Health, Ardmore, Pennsylvania

Jonathan L Gleason

Thomas Jefferson University

Bruce A Meyer

Thomas Jefferson University

Follow this and additional works at: https://jdc.jefferson.edu/healthpolicyfaculty

Part of the Public Health Commons

Let us know how access to this document benefits you

\section{Recommended Citation}

Nash, David B.; Angelo, Mark; Nash, Esther J; Gleason, Jonathan L; and Meyer, Bruce A, "We Know Health Is Not Elective: Impacts of COVID-19." (2020). College of Population Health Faculty Papers. Paper 102.

https://jdc.jefferson.edu/healthpolicyfaculty/102

This Article is brought to you for free and open access by the Jefferson Digital Commons. The Jefferson Digital Commons is a service of Thomas Jefferson University's Center for Teaching and Learning (CTL). The Commons is a showcase for Jefferson books and journals, peer-reviewed scholarly publications, unique historical collections from the University archives, and teaching tools. The Jefferson Digital Commons allows researchers and interested readers anywhere in the world to learn about and keep up to date with Jefferson scholarship. This article has been accepted for inclusion in College of Population Health Faculty Papers by an authorized administrator of the Jefferson Digital Commons. For more information, please contact: JeffersonDigitalCommons@jefferson.edu. 


\section{Expanded Commentary}

\section{We Know Health is Not Elective -- Impacts of Covid-19}

David B. Nash, MD, MBA

Jefferson College of Population Health, 901 Walnut Street, 10 ${ }^{\text {th }}$ floor, Philadelphia, PA 19107 David.nash@jefferson.edu; 215-955-

Mark Angelo, MD MHA

Delaware Valley Accountable Care Organization, 259 N. Radnor-Chester Road, Suite 290, Radnor, PA 19087

AngeloMa@dvaco.org; (610) 225-6233

Esther J. Nash, MD, FACP

Consultant, Population Health, 217 E. Montgomery Avenue, Ardmore, PA 19003

Enashmd@gmail.com; 6106598977

Jonathan L. Gleason, MD

Jefferson Health, 1101 Market Street, 31 $1^{\text {st }}$ floor, Philadelphia, PA 19107

Jonathan.gleason@jefferson.edu; (540) 798-2602

Bruce A. Meyer MD MBA

Jefferson Health, 1101 Market Street, 31 fl floor, Philadelphia, PA 19107

Bruce.Meyer@Jefferson.edu; (215) 955-5697

Running head: We Know Health Is Not Elective - Impacts of COVID-19

Keywords: pandemic, economic impact, health equity, health care waste, value-based care, ACO 


\section{Abstract}

Several months into the impact of the global COVID-19 pandemic, the authors use the framework of "radical uncertainty" and specific regional health care data to understand current and future health and economic impacts. Four key areas of discussion included are:

(1) How did structural health care inequality manifest itself during the closure of all elective surgeries and visits?; (2) How can we really calculate the so-called untold burden that resulted from the closure, with a special emphasis on primary care?; (3) The Pennsylvania experience - using observations from the population of one major delivery ecosystem (Jefferson Health), a major accountable care organization (Delaware Valley ACO), and statewide data from Pennsylvania; and (4) What should be the priorities and focus of the delivery system of the future given the dramatic financial and clinical disruption of COVID19 ? 


\section{Introduction}

The current pandemic is a classic example of what economists call "radical

uncertainty,"1 ${ }^{1}$ which describes a world that is just too complex to be adequately captured in

models. This is a world of "known unknowns" and "unknown unknowns." In the context of the

pandemic, a known unknown might be "What percentage of persons would heed a warning to

wear a mask in public?" An unknown unknown is typically a cumulative impact of multiple

known unknowns. For example, what could be the unique social and economic repercussions

from shutdowns on a particular demographic group, profession, or industry ${ }^{1}$ - as there is no

meaningful way to predict or to assign probabilities. Or said more simply, we don't even know

what we don't know!

The theory of radical uncertainty also notes how to face these challenges. We tackle

unknown unknowns by "building resilience while encouraging rival teams of experts." ${ }^{1}$ We

approach a known unknown by first learning from others (ie, other nations' approaches to the

pandemic), while also investing in finding out new information. Finally, the theory notes that all

of this needs to be done fast. This expanded commentary will use the radical uncertainty 
framework to explore some key issues as they relate to the functioning of the health care system in the United States, both during March/April 2020 and in the aftermath.

What are the health-related consequences of being forced to close most non-COVID-19-

related health care services for $8-12$ weeks, in a nation that spends nearly $20 \%$ percent of its

gross domestic product on the health care industry? This is a known unknown with some data that can be extrapolated from utilization statistics and distilled from the modest research literature on the follow-up from natural disasters such as severe hurricanes.

The unknown unknowns in this context have more to do with unpredictable human behavior, the patchwork quilt payment system in health care, federal government decisionmaking (or lack thereof) during a massive public health crisis, and a health care industry that Nobel Laureates in economics have recently described as an "engine of inequality." ${ }^{2}$ There is no validated way to apply probabilities here.

The issues addressed in this commentary will include: 
- Part 1: Structural Inequality. How did structural inequality manifest itself during the

closure of all elective surgeries and visits?

- Part 2: The Untold Burden - Some Known Unknowns. How can we really calculate the so-called untold burden that resulted from the closure (with a special emphasis on primary care)?

- Part 3: The Pennsylvania Experience. What was the impact, both from a utilization and a health-related perspective, using observations from the population of one major delivery ecosystem (Jefferson Health), a major accountable care organization (ACO; Delaware Valley ACO), and statewide data from Pennsylvania.

- Part 4: Prospects for the Future. What should be the priorities and focus of the delivery system of the future, given the dramatic financial and clinical disruption of COVID-19?

\section{Part 1: Structural Inequality}


This commentary is not about the need to get back to business as usual, nor do the authors believe that when elective procedures return to pre-pandemic levels, all will be well.

The authors believe that to truly embrace an ethos of improving "health," we must go beyond the notion that health means a return to overutilization, waste, medical error, and flagrant inequities in the delivery system.

Leading physician thinkers of our age, such as Siddhartha Mukherjee ${ }^{3}$ and Donald Berwick, ${ }^{4}$ have been very articulate in their recent pandemic-related commentaries. While we are not going to review every detail, some background is helpful to set the context for our discussion. Mukherjee ${ }^{3}$ decries current system failings such as the national scandal of health care coverage that leaves millions of Americans uninsured. He describes shortages of key supplies that were "known," a just-in-time inventory system that was immediately crippled by the never before seen influx of critically ill patients, and of course, the electronic medical record systems that in his words, "actively obstruct patient care."

Berwick ${ }^{4}$ reminds us, again, that "students of either health or justice are not at all surprised to read headlines about the unequal toll of Covid-19 on the poor, the 
underrepresented minorities, the marginalized, the incarcerated, the indigenous

peoples...Anyone who studies the toll of vast inequality, in either the U.S. or the world at large, could have predicted those disproportionate deaths with absolute certainty long before they occurred." In short, Berwick describes the pandemic in terms of a known outcome from a previously unknown cause. Certain communities of color suffered a disproportionate incidence of COVID-19 hospitalizations and death. ${ }^{5}$ In addition, the lack of any coherent national primary care strategy only exacerbated these shortcomings. We will explore and quantify these issues, and their impact on health.

\section{Part 2: The Untold Burden - Some Known Unknowns}

It is extremely difficult to calculate, with any statistical certainty, what we are calling the untold burden in this commentary. That is, for example, the numbers of "preventable deaths" of patients who - for a multitude of reasons - failed to seek medical care in March or April

2020. From a health services research perspective, it also is complicated to quantify the 
"health-related opportunity cost" derived from failures to receive health-related counseling, appropriate medications, and certain emergent procedures such as placement of a cardiac stent.

Headlines about the untold burden in the March/April 2020 time period were quite varied, and the stories they reported were as well. The headlines and data generally fell into 3 categories: reports of clinical declines in usual urgent/emergent care with sample case reports, attempts to quantify the untold burden with descriptive utilization data, and ultimately warning the public not to ignore certain signs and symptoms.

For example, excellent case reports appeared in the New England Journal of Medicine by authors such as Rosenbaum in an essay entitled "The Untold Toll - The Pandemic's Effects on Patients Without Covid19." ${ }^{6}$ Still others, such as respected health services researcher Harlan Krumholz, writing in The New York Times asked poignantly, "Where Have All the Heart Attacks Gone?"7 Both authors helped to stimulate a national conversation on this issue, but neither provided descriptive data regarding the scope and scale of the impact. Even famous politicians, 
such as former Nebraska governor and US Senator Bob Kerrey, opined in The Wall Street Journal that "Elective Surgery Saves Lives."

The observational reports incorporating utilization data delivered worrisome news by analyzing electronic databases and reassessing data from respected sources such as the National Center for Health Statistics (NCHS). For example, writing in The New York Times, Hoffman ${ }^{9}$ noted a dangerous drop in well-baby visits, with an attendant decrease in vaccination rates. She reported a $50 \%$ decline in the administration of measles, mumps, and rubella shots across 1000 pediatric offices. A team from Yale and The Washington Post, ${ }^{10}$ made national headlines by evaluating NCHS data and decrying the underreporting of all non-COVID deaths in multiple states.

The last category of untold burden press articles began to appear at the end of April 2020, no doubt spurred by observed adverse outcomes and the provider community realizing just how "empty" their offices and the local emergency rooms (ERs) really were. Writing in a page 1 story in The Philadelphia Inquirer, Gantz and Ruderman openly confronted the fear factor that many persons had about visiting any hospital, despite worrisome neurologic and 
cardiovascular symptoms being experienced at home. ${ }^{11}$ This fear factor also was explored in another Inquirer piece describing the plight of local cancer patients now forced to get certain kinds of complex chemotherapy at home. ${ }^{12}$

Anecdotal evidence of persons collapsing at home, rather than visiting an ER, began to enter our collective consciousness, and providers urged potential patients to seek treatment.

The true cost to the health of the public has yet to be calculated. In addition, reports of significant increases in "dead on arrival" emergency medical technician visits after 911 calls have been seen in multiple cities (email communication; Thomas Farley, MD MPH, Commissioner, City of Philadelphia Department of Health; June 5, 2020).

The untold burden in primary care

Can we better quantify the untold burden in the outpatient setting, especially as it relates to primary care? We believe the answer is yes, and we will explore this in 3 ways: the 
health consequences of missed in-person primary care visits and the use of telemedicine, the economic impact, and some thoughts about the future of primary care.

Telemedicine visits increased dramatically nationwide ${ }^{13}$ during the time frame under discussion. Surely, via telemedicine many patients were able to renew their prescriptions, get expert advice, possibly avoid an ER visit, and equally importantly, feel reassured. The vast cultural change - on the part of providers, consumers, and payers, as it related to the rapid diffusion and uptake of telemedicine services - was impressive. However, there is no coordinated national tracking system for assessing telemedicine outcomes.

We therefore surmise that these telemedicine visits had a positive clinical impact, but epidemiologic data to support that assertion are scant. We believe that the core components of primary care service delivery - patient counseling, preventive screening, chronic condition management, and symptom follow-up - were disrupted significantly. The downstream effects of the failure to obtain mammograms, colonoscopies, diabetic eye exams, and annual wellness 
visits, as well as ongoing management of chronic illnesses, are a known unknown in our view.

At best, we might be able to assign some probabilities to all of this.

On a national scale, the absence of continuous primary care counseling, as it relates to

promoting a healthy lifestyle (ie, smoking cessation, obesity mitigation, increase in physical

activity), will have lasting effects. Viewed from a larger perspective, coupling the lack of a

national primary care strategy with a multi-month absence of continuous attention to

prevention may lead to a greater chronic disease burden that, sadly, will continue to threaten

our preparedness for another possible surge. Recent research ${ }^{14}$ has elegantly reconfirmed the

association of a healthy lifestyle with the number of years lived without a major chronic

disease. From a population health perspective, a healthier population with a cultural and

system-wide emphasis on "obtaining and sustaining health" will be far better prepared for any

subsequent pandemic.

Economic impact on primary care 
The economic impact of the shutdown on primary care has been rapid, and dramatic in

scale. As reported in The New York Times, "the situation facing front line physicians is dire." 15

Some estimates note that as many as 60,000 physicians in family medicine may no longer be

working in their practices by June. Respected groups such as the Commonwealth Fund noted

that "outpatient offices faced a perfect storm of stay-at-home orders, infection risks, and

severe financial stress while still trying to deliver desperately needed clinical care." ${ }^{16}$ The Fund,

along with Harvard University researchers and Phreesia, a health technology company, noted a

startling $60 \%$ decline in visits to all ambulatory practices, with most of this occurring in a 2 -

week period. They further noted that despite the growth in telemedicine, it alone accounted

for "a tiny fraction of the lost ambulatory visits." 16

Major national membership organizations, representing mostly physicians in ambulatory

practice settings, such the Medical Group Management Association, the Primary Care

Collaborative, and even the American Medical Association, all asked Congress to provide

financial aid in order "to help keep physician practices afloat."17 
Reputable national consulting companies such as PricewaterhouseCoopers, capable of conducting widespread physician and consumer health-related surveys, noted that during March/April 2020, "78 percent of these consumers (surveyed nationally), would skip at least one visit such as a well-visit, maintenance visit for a chronic illness, elective procedure or

recommended lab test or screening."18 Similarly, other consulting companies such as Luma ${ }^{19}$ noted a record $108 \%$ increase in nonurgent care cancellations nationwide in March and April.

Finally, some maintain ${ }^{20}$ that 1 in 5 primary care practices nationwide, could close permanently - clearly a known unknown.

The future of primary care

While full discussion of the future of primary care is beyond the scope of this commentary, in our view, primary care services will never look the same in the new world of returning to work with COVID-19.

We believe that there likely will be further consolidation in primary care, with many of the smaller, largely fee-for-service, private practices being purchased by payers ${ }^{21}$ (for-profit 
managed care organizations) who in the near term have increased resources available because

they did not have to pay for medical services for beneficiaries who did not visit the health care

system. In a uniquely American "solution" to this dramatic marketplace disruption, some

payers likely will consolidate and even expand their market share. The share of primary care

practices not already part of multi-provider organizations able to bear financial risk, such as

ACOs, likely will increase.

Finally, we also note that other stakeholders, such the retail clinic giants Walmart ${ }^{22}$ and CVS Health, ${ }^{23}$ are moving ahead aggressively to expand their retail (primary care) footprints "as physician practices face a cash crunch." We knew that the primary care practices still primarily working under a fee-for-service financial model would be ill-suited to handle a national health emergency - a known unknown. In another indicator, CVS Health is warning of a non-virus health crisis related to delay of routine care as evidenced by a dramatic drop in per store prescription refills. ${ }^{24}$

\section{Part 3: The Jefferson Health, DVACO and Pennsylvania Experience and Impact}


In this part, we will draw on past and current utilization data from 3 sources to describe the Jefferson ecosystem. These include the Pennsylvania Health Care Cost Containment Council ("HC4"), a 30-year-old state-mandated data collection and analysis center in Harrisburg, PA; Jefferson Health, a 14-hospital integrated delivery system with the largest market share in the Philadelphia region; and the Delaware Valley ACO (DVACO), which is a joint venture between Jefferson Health and Main Line Health System (a community-based, multi-hospital integrated delivery network). The goal of Part 3 is to use past and current actual utilization data to attempt to quantify the untold burden discussed earlier.

At the state level, pre COVID-19, the nearly 300 acute care hospitals in Pennsylvania (during the fiscal year ending on June 30,2019 ) saw their uncompensated care rise nearly $10 \%$; this was the first substantive increase in 5 years. Operating margins remained flat. More than a third of all the hospitals lost money on business operations and many more made less than a $4 \%$ margin. ${ }^{25}$ By April 20, 2020, one year later, the Hospital and Healthsystem Association of Pennsylvania was predicting cumulative statewide hospital operating losses in excess of \$10B in 2020 because of the pandemic. ${ }^{26}$ 
To better understand the dramatic change in statewide hospital utilization during

March/April 2020, we will compare HC4 utilization data from roughly the same time period in

2019 to 2020. There is insufficient space here to describe each type of statewide inpatient

discharge; therefore, we will focus on major inpatient conditions first, and then key ambulatory

visits second, exclusively in Philadelphia county (one of 67 counties in the Commonwealth of

Pennsylvania and home to Jefferson Health).

According to a custom analysis undertaken by HC4 staff for this commentary (Table 1), we note results for all hospitals in Philadelphia County (which would include all of the other academic medical centers such as Penn Medicine, Drexel, and Temple) in April 2019 for the following conditions:

- Heart Attack - Angioplasty/Stent (the patient underwent angioplasty/stent and had a principal diagnosis of acute myocardial infarction [AMI]).

- Heart Attack - Medical Management (patients with a principal diagnosis of AMI who received medical management as the treatment). 
- COPD (patients with a principal diagnosis of chronic obstructive pulmonary disease).

- Diabetes - Medical Management (patients with a principal diagnosis of diabetes who received medical management as the treatment, with no amputations).

- Heart Failure (patients with a principal diagnosis of heart failure).

- Stroke (patients with a principal diagnosis of stroke).

[Table 1 here]

Table 1 displays typical, high-level, monthly utilization data and illustrates the countywide utilization as the baseline.

Table 2, again using HC4 data, shows that in a typical month, April 2019, in Philadelphia County alone, there were more than $10 \mathrm{~K}$ ambulatory surgery claims in hospital-based ambulatory centers for which cancer was the principal diagnosis. We believe that this is helpful to understand the urgency of some ambulatory surgeries in typical times. It also begs the important question of how the proportion of these cases might change following the pandemic. 
[Table 2 here\}

As we attempt to quantify the untold burden of care, recognizing that - at least in

Philadelphia County - the April 2020 data for both inpatient care and ambulatory surgery would

be hovering near zero, it gives us pause to reflect on the true suffering that patients have

endured at home, in one month, in one county, in one of America's largest cities.

Using countywide data from $\mathrm{HC} 4$ as context, we now focus on Jefferson Health with a

similar lens - March/April 2019 vs March/April 2020 utilization data. Where available, we also

will cite some published national data for MI and stroke. In a typical pre-COVID-era month,

such as April 2019, the Jefferson enterprise would have seen in excess of 41K emergency room

visits; in April 2020, this number dropped by close to $64 \%$ (Table 3).

[Table 3 here]

Given these precipitous drops in visits, scores of possible MI and stroke patients - for a

variety of reasons - opted to remain at home rather than seek ER care, resulting in a $>36 \%$

decrease in total discharges for $\mathrm{Ml}$ and stroke between 2019 and 2020. 
Taken together, the dramatic drop in overall ER visits coupled with stroke and MI total

discharges in the Jefferson data are consistent with recent published reports during April 2020.

For example, using a national commercial neuroimaging database, Kansagra and colleagues ${ }^{27}$

found "that the collateral effect on Covid-19 was a decrease of approximately 39 percent in the number of patients who received evaluations for acute stroke between 2 recent epochs in U.S.

hospitals."

Garcia and colleagues ${ }^{28}$ looked at the decrease in the total number of cardiac

catheterization laboratory activations to treat an acute $\mathrm{MI}$ by means of primary percutaneous

coronary intervention at 9 high-volume centers, as a proxy for the nation. Here again, these

authors found a $38 \%$ reduction in US cardiac catheterization activations post Covid-19. The

Jefferson enterprise data are comparable to both national studies and as a result, our findings

are reproducible.

As shown in Table 3, the Jefferson enterprise also saw dramatic reductions in ambulatory and radiology utilization. 
DVACO - Completing the PIcture

DVACO is comprised of approximately 2000 providers, more than 700 of whom are

primary care providers. With nearly 90,000 Medicare fee-for-service Medicare Shared Savings

Plan (MSSP) beneficiaries and nearly 150,000 additional risk-contract lives from other payers, it

is among the largest ACOs in the United States.

The DVACO population experienced profound decreases in acute care utilization for the time period encompassing the COVID-19 public health emergency in the area. For the 6-week period beginning March 13, 2020, while seeing the initial increase in Covid-19-related cases presenting to the health system, the DVACO population experienced an overall $39 \%$ decrease in hospital inpatient service utilization and a $42 \%$ decrease in ER utilization. If acute care presentations that include a COVID-19 diagnosis are removed from the measurement, COVID19 inpatient admissions and ER utilization decrease even more, by $43 \%$ and $45 \%$, respectively. The Centers for Medicare and Medicaid Services (CMS) annually calculates "avoidable" ER visits and admissions for MSSP beneficiaries. This provides a third-party calculation of acute 
coronary and stroke utilization. In 2019, the DVACO MSSP population experienced more than 3400 "unavoidable" ER visits and 4700 admissions to acute care hospitals, more than 1300 of which represented acute coronary syndrome or unstable angina, heart failure, or acute stroke.

The CMS calculation regarding the diagnoses of those presenting to acute care for the same time period in 2020 are still forthcoming and is expected to be markedly reduced.

These data further elucidate the extent of the untold clinical burden. We likely will not fully understand the downstream effects of this massive decrease in utilization for months, or possibly years, given the limitation in measuring true clinical outcomes.

\section{Part Four: Prospects for the Future}

We maintain that health - as our most precious resource - is not "elective." In fact, maintaining and improving health should be the core goal for our entire industry. As we transform the system to focus on health, what are the prospects for the future? 
Some well-known leaders, such as the CEO of Jefferson Health, have likened this

prospect to "healthcare's Amazon moment" ${ }^{29}$ - meaning essentially that the pandemic is the

"big disruption" that will force health care to finally join the consumer revolution.

Still other recognized observers, such as the President of the Milbank Memorial Fund, ${ }^{30}$

have rightly said, "Don't rebuild the health system, reorient it....Why rush to rebuild a system

that is leaving us so vulnerable to this pandemic?" He adds that rather than deploying (health

care workers) back into our "treatment-oriented, administratively burdensome delivery system,

they can be engaged in the work of prevention, primary care, and community based services -

roles with greater impact on societal health."

Part 4 includes a quick review of another aspect of the untold burden on health care -

the economic consequences of the near complete shutdown of non-COVID-19-related care-

and then touches on the prospects for future transformation by highlighting the political,

practice-related, technologic, and structural issues that must be confronted. 
The economic component of the untold burden is staggering, and somewhat

counterintuitive. The unprecedented decline in health spending could, itself, lead to an

economic downturn. ${ }^{31}$ While elective care is slowly restarting, this is a known unknown as the

probability that patients will return for routine care hovers between $30 \%$ and $60 \%,{ }^{32}$ depending

on the study one cites.

What remains counterintuitive are the health care-related job losses. Hundreds of

hospitals ${ }^{33}$ have already furloughed or laid off nearly 1.4 million employees. Many of the

nation's most prestigious health care institutions are on this list. In a nutshell, "the industry

used to be recession-proof. Not anymore. The postponement of elective procedures has

crushed the bottom line."33

Politically, not only has the pandemic highlighted the gap between the haves and have-

nots, it has re-elevated health care as a central, national security, and election year issue. As

commentator Paul Keckley ${ }^{34}$ has observed, the majority of Americans care about the healthcare

system, and there will be "intensified sensitivity among consumers how profit is defined,

created and used, how executives are paid, how boards operate...and whether their values 
really matter." He notes that consumers will demand a new "ethicality" from health care organizations. ${ }^{35}$

Although clearly beyond the scope of this commentary, respected national health policy research groups have issued a political rallying cry - calling for a complete reexamination of the basic tenets of social justice, worker rights, thriving and equitable communities, and inevitably, an emphasis on the return to purchasing value (email communication; M. Schaps; April 21, 2020).

We contend that a pragmatic and readily implementable plan to return to "value," especially in the context of the data presented in Part 3, would be to return our focus to reducing the fraction of "waste" in health care, which comprises unnecessary or questionably effective services. We have repeatedly seen evidence ${ }^{36}$ that upward of one quarter to one third of all health care spending is of little or no value - costing the system nearly \$1 trillion.

Although we are saddened by the untold clinical burden described herein, it is irrefutable that some of those cardiac stents that would have been placed, had non-COVID-related care been 
available, would be of questionable value. ${ }^{37}$ It is also likely that the reduction in utilization was greater than the estimates of health care that is of little or no value.

To achieve real value, not only must we recommit to reducing waste, we also must recognize that 400,000 deaths ${ }^{38}$ occur annually in the United States because of errors in care an unacceptable number that hopefully will not be equaled by the number of COVID-19 deaths. Perhaps the combined reduction in inappropriate utilization and reemphasis on safety will have a welcome resurgence in the near term. Given the unprecedented measures that were taken with staff working in unfamiliar environments and patients receiving care in nontraditional spaces, it is likely that some forms of preventable harm increased during the pandemic in areas that were hard hit by COVID-19. We may learn that hospital-acquired infections rose at health systems that were heavily impacted or fell at hospitals that were left empty. Experts recognized that errors continued to occur during the coronavirus crisis and they note "we can do better next time." 39 Having stated this, the economic consequences to the finances of the health care system of removing $\$ 1$ trillion of revenue will have to be grappled with by both providers and payers if a sustainable path to value is to be achieved. 
We believe that there is no single technologic fix for our system in the near term - no

"switch" that, once flipped, will magically solve our future challenges. Beyond widespread use

of telemedicine, respected policy organizations such as the Committee for Economic

Development (CED) of the Conference Board (where one of the authors [DBN] is a trustee)

believe that innovation must lead the way to COVID-19 recovery. ${ }^{40}$ For example, CED calls for

"reducing the digital divide and replacing outdated public sector IT [information technology]

systems."

We believe that is has never been clearer that the sociotechnical clinical operating system of modern health care should be more agile and capable. Technology has enabled much of the COVID-19 response, but this work has been difficult. Systems engineering must continue to be a focus. ${ }^{41} \mathrm{~A}$ slew of tech companies are part of this systems engineering ecosystem.

We believe that COVID-19 could spur greater IT interoperability and thus, better data and analysis---which hopefully will lead to better predictions, better resource allocation, and better health-related outcomes for other crises of that lay ahead. Although somewhat 
counterintuitive, "throughout the Great Depression, General Electric (GE) and its subsidiary

Radio Corporation of America (RCA) continued to invest in its (television) development. The

result was RCA's dominance of the medium in the decades that followed." 42 This historical

lesson is the backdrop for the current growth experienced by the "FAAAM" companies -

Facebook, Amazon, Alphabet, Apple, and Microsoft - as they innovate out of the pandemic.

When Microsoft (telephone communication; D. Rhew; May 21, 2020), for example, links a

health care delivery organization such as Providence (headquartered in Renton, WA) with the

grocery store giant Kroger, and can assess a patient's level of food insecurity and then deliver

supplies for self-isolation - all digitally - that is innovating out of the crisis.

Finally, key structural issues remain that we view as central to the future transformation

of the system. Perhaps large for-profit health insurers and government payment models should

prioritize support for primary care practices. ${ }^{43}$ And an argument can be made to expand

Medicaid $\mathrm{ACOs}^{44}$ to better serve populations who were disproportionately devastated by the

pandemic surge. We have seen rapid growth in the number and type of for-profit social

determinants of health companies. ${ }^{45}$ 
However, we view these changes as largely incremental. Ultimately, the true structural

change we seek is best described as "vertical integration," which experts have recently

described as the model best suited for owning the whole patient - as it "requires aligning

financial incentives between providers, payers, and patients; establishes holistic access by

providers and payers to patient health data, coupled with analytics tools to guide care

management and coordination; and developing seamless and personalized consumer

experiences around administration of care and coverage." ${ }^{46}$ We enthusiastically concur that

such a model has "the potential to lower health care costs, improve care quality and outcomes,

and enhance the patient experience." This type of sweeping change also would require a

revamping of the systems of payment for health care in order to be sustainable. The COVID-19

crisis has introduced great uncertainty into the risk predictions of ACOs. Based on a survey by

the National Association of ACOs, ${ }^{47}$ the willingness of these value-based care organizations to

continue participation in these payment models is thus now in the known unknown category

itself. 
We know we must work hard to maintain and improve health because it is not

"elective." We borrowed some concepts from radical uncertainty to help frame this discussion.

We acknowledge that there was a significant untold burden - economic, clinical, social - for our

entire society during March/April 2020 that will have repercussions far into the future. We

attempted to quantify aspects of this burden.

Some important known unknowns remain, including when, and at what level of

participation, will our non-COVID patients return to the health care system. We miss them, and

we urge them to return.

The remaining unknown unknowns, to which we cannot yet assign any probabilities, are

troubling. There likely are many unknown unknowns related to social distancing, handwashing,

and - most importantly - wearing face masks until a definitive treatment or vaccine(s) is

developed. If we are unable to create the cultural change necessary to successfully tackle these

unknown unknowns, we shudder to think of the clinical and economic consequences. Further

concepts including vaccination possibilities and prolonged or second surges of COVID-19 add

yet another layer of uncertainty. 
We recognize that this analysis has several important limitations given that we describe one regional health system and one ACO in one state, and only a handful of non-COVID clinical conditions. We extrapolated the data and perhaps drew some inappropriate conclusions. It is certainly possible that factors other than the COVID pandemic contributed to the observed changes in health care utilization, but given their suddenness and magnitude, COVID is most likely the key driver.

As we write, Philadelphia County is slowly beginning to reopen, after nearly 75 days of sheltering at home. Slightly more than 75 years ago, Winston Churchill declared "Forward, unflinching, indomitable, till the whole task is done and the whole world safe and clean." ${ }^{48}$ It seems like a fitting description of our pending transformation. 


\section{Acknowledgements}

The authors would like to acknowledge the following persons and organizations for all their help with this manuscript. Mr. Joe Martin and Ms. Flossie Wolf, from the PA Health Care Cost Containment Council (HC4) provided a custom state and county analysis. Ms. Monica Doyle, and others, from Jefferson Health, provided key utilization data. Dr. Ryan Vass, from the Delaware Valley ACO, provided both utilization data and key insights for the paper. Ms. Deborah Meiris, the Managing Editor, provided invaluable copyediting to strengthen the entire paper. We are also grateful to the anonymous reviewers who gave us extremely candid feedback on prior drafts.

\section{Author Disclosure Statement}

The authors declare that there are no conflicts of interest. The conclusion and opinions expressed herein are solely those of the authors and do not represent official policies of any organization or corporation.

\section{Funding}

No funding was received for this article. 


\section{References}

1. Collier P. The problem of modelling: Public policy and the coronavirus. Times Literary Supplement. April 24, 2020. https://www.the-tls.co.uk/articles/problem-modelling-public-policy-coronavirus-paulcollierl. Accessed May 2, 2020.

2. Case A, Deaton, A. America can afford a world-class health system. Why don't we have one? The New York Times. April 19, 2020. https://www.nytimes.com/2020/04/14/opinion/sunday/Covid-inequalityhealth-care.html. Accessed April 19, 2020.

3. Mukherjee, S. What the coronavirus crisis reveals about American medicine. The New Yorker. May 4, 2020. https://www.newyorker.com/magazine/2020/05/04/what-the-coronavirus-crisis-revealsabout-american-medicine. Accessed May 2, 2020.

4. Berwick DM. Choices for the "new normal." JAMA. Published online May 4, 2020. doi:10.1001/jama.2020.6949

5. Millett GA, Jones AT, Benkeser D, et al. Assessing differential impacts of Covid-19 on black communities. Annals of Epidemiology 2020;47:37-44. doi:

https://doi.org/10.1016/j.annepidem.2020.05.003

6. Rosenbaum L. The untold toll - the pandemic's effects on patients without Covid-19. N Engl J Med. 2020;382:2368-2371. doi: 10.1056/NEJMms2009984

7. Krumholz H. Where have all the heart attacks gone? The New York Times. April 6, 2020. https://www.nytimes.com/2020/04/06/well/live/coronavirus-doctors-hospitals-emergency-care-heartattack-stroke.html. Accessed April 6, 2020.

8. Kerrey B. 'Elective’ Surgery Saves Lives. The Wall St. Journal. April 21, 2020. https://www.wsj.com/articles/elective-surgery-saves-lives-11587400926. Accessed April 21, 2020.

9. Hoffman J. Vaccine rates drop dangerously as parents avoid doctor's visits. The New York Times. April 23, 2020. https://www.nytimes.com/2020/04/23/health/coronavirus-measles-vaccines.html. Accessed April 23, 2020.

10. Brown, E, Tran, A, Reinhard, B, Ulmanu, M. U.S. deaths soared in early weeks of pandemic, far exceeding number attributed to Covid-19. The Washington Post. April 27, 2020. https://www.washingtonpost.com/investigations/2020/04/27/Covid-19-death-tollundercounted/?arc404=true. Accessed April 27, 2020. 
11. Gantz S, Ruderman W. Fearing coronavirus at hospitals, patients with heart attacks or strokes may be staying away, doctors say. The Philadelphia Inquirer. April 21, 2020.

https://www.inquirer.com/health/coronavirus/coronavirus-Covid-19-delayed-care-heart-attack-stroke20200421.html. Accessed April 21, 2020.

12. McCullough M. Coronavirus threat spurs movement of cancer care into homes. The Philadelphia Inquirer. April 15, 2020. https://www.inquirer.com/health/coronavirus/coronavirus-shifts-cancertreatment-from-hospitals-to-homes-20200415.html. Accessed April 15, 2020.

13. Hollander J, Carr B. Virtually perfect? Telemedicine for Covid-19. N Engl J Med. 2020;382:1679-81. doi:10.1056/NEJMp2003539

14. Nyberg S, Singh-Manoux A, Pentti J, et al. Association of healthy lifestyle with years lived without major chronic diseases. JAMA Intern Med. 2020;180:760-768. doi:10.1001/jamainternmed.2020.0618

15. Abelson, R. Doctors Without Patients: 'Our Waiting Rooms Are Like Ghost Towns'. The New York Times. May 5, 2020. https://www.nytimes.com/2020/05/05/health/coronavirus-primary-caredoctor.html. Accessed May 5, 2020.

16. Schneider C, Shah T. "Pandemic Shock Threatens to Undermine Outpatient Care," To the Point (blog), Commonwealth Fund, Apr. 23, 2020. https://doi.org/10.26099/nth2-xg40. Accessed May 3, 2020.

17. Shinkman R. Doctors say Covid-19 has slashed patient volumes, made finances shaky. Healthcare Dive. April 13, 2020. https://www.healthcaredive.com/news/doctors-say-Covid-19-has-slashed-patientvolumes-made-finances-shaky/575876/. Accessed May 3, 2020.

18. PwC Health Research Institute. The Covid-10 pandemic is influencing consumer health behavior. Are the Changes Here to Stay? April 2020. https://www.pwc.com/us/en/library/Covid-19/assets/pwc-ushealth-C-19-survey chartpack.pdf. Accessed May 3, 2020.

19. Ekram, T. New Luma Health Report Reveals COvid-19 is Fast-Tracking Healthcare Innovation and Changing Care Delivery. lumahealth blog. April 28, 2020. https://www.lumahealth.io/blog/new-lumahealth-report-reveals-Covid-19-is-fast-tracking-healthcare-innovation-and-changing-care-delivery/. Accessed May 3, 2020. 
20. Pifer R. $1 / 5$ of primary care practices could close within next month as US mulls reopening economy. Healthcare Dive. April 20, 2020. https://www.healthcaredive.com/news/15-of-primary-care-practicescould-close-within-next-month-as-us-mulls-reo/576351/. Accessed May 10, 2020.

21. Trentmann N. Some Insurers Flex Balance Sheets to Help Hospitals, Doctors Amid Pandemic. Wall St. Journal. May 4, 2020. https://www.wsj.com/articles/some-insurers-flex-balance-sheets-to-helphospitals-doctors-amid-pandemic-11588510801. Accessed May 4, 2020.

22. Ellison A. Walmart Health expands as physician practices face cash crunch. Becker's Hospital CFO Report. May 6, 2020. https://www.beckershospitalreview.com/finance/walmart-health-expands-asphysician-practices-face-cash-crunch.html. Accessed May 10, 2020.

23. Paavola A. CVS' goal of opening 1,500 HealthHubs on track despite pandemic. Becker's Hospital Review. May 7, 2020. https://www.beckershospitalreview.com/pharmacy/cvs-goal-of-opening-1-500healthhubs-on-track-despite-pandemic.html. Accessed May 10, 2020.

24. Terlep S. CVS Warns of Surge in Non-Coronavirus Health Problems. The Wall St. Journal. May 7, 2020. https://www.wsj.com/articles/cvs-sales-jump-as-shoppers-stock-up-on-medication-11588765912. Accessed May 7, 2020.

25. Pennsylvania Health Care Cost Containment Council. Financial Analysis 2019: General Acute Care Hospitals. Published April 15, 2020.

http://www.phc4.org/reports/fin/19/docs/fin2019report volumeone.pdf. Accessed May 12, 2020.

26. George J. Coronavirus-related losses for Pennsylvania hospitals to top $\$ 10 B$ this year, report says. Philadelphia Business Journal. April 20, 2020.

https://www.bizjournals.com/philadelphia/news/2020/04/20/coronavirus-related-losses-forpennsylvania.htm|\#i/6727232. Accessed April 20, 2020.

27. Kansagra A, Goyal M, Hamilton S, Albers G. Collateral effect of Covid-19 on stroke evaluation in the United States. N Engl J Med 2020;383:400-401. doi: 10.1056/NEJMc2014816

28. Garcia S, Albaghdadi M, Meraj P, et al. Reduction in ST-segment elevation cardiac catheterization laboratory activations in the United States during Covid-19 pandemic. J Am Coll Cardiol 2020;75:28712872. doi: 10.1016/j.jacc.2020.04.011 
29. Dyrda L. 'This is healthcare's Amazon moment': Dr. Stephen Klasko's 5 predictions on healthcare delivery post-Covid-19. Becker's Hospital Review April 1, 2020.

https://www.beckershospitalreview.com/hospital-management-administration/this-is-healthcare-samazon-moment-dr-stephen-klasko-s-5-predictions-on-healthcare-delivery-post-Covid-19.html. Accessed May 10, 2020.

30. Koller C. Don't Rebuild the Health System, Reorient It. Milbank Memorial Fund President's Blog May 20, 2020. https://www.milbank.org/2020/05/dont-rebuild-the-health-system-reorient-it/. Accessed May 16, 2020.

31. Miller G, Hughes-Cromwick P. Perspective: Unprecedented Decline in Health Spending is Leading the Economic Downturn. Altarum Newsroom April 30, 2020 https://altarum.org/news/lower-personalconsumption-expenditures-driven-by-health-care-spending. Accessed May 16, 2020.

32. Abelson, R. Hospitals are Eager to Restart Elective Care, a Big Part of Their Revenue. The New York Times May 10, 2020. https://www.nytimes.com/2020/05/09/health/hospitals-coronavirusreopening.html. Accessed May 10, 2020.

33. Sanger-Katz M. Why 1.4 Million Health Jobs Have Been Lost During a Huge Health Crisis. The New York Times May 8, 2020. https://www.nytimes.com/2020/05/08/upshot/health-jobs-plummetingvirus.html. Accessed May 10, 2020.

34. Keckley P. Looking Ahead: The Pivot to Healthcare Politics and What to Expect. The Keckley Report May 4, 2020. https://www.paulkeckley.com/the-keckley-report/2020/5/4/looking-ahead-the-pivot-tohealthcare-politics-and-what-to-expect. Accessed May 16, 2020.

35. Keckley, P. In Healthcare, Now and Near are on the Radar, But it's Back to the Drawing Board for Far. The Keckley Report April 21, 2020. https://www.paulkeckley.com/the-keckley-report/2020/4/21/inhealthcare-now-and-near-are-on-the-radar-but-its-back-to-the-drawing-board-for-far. Accessed May $16,2020$.

36. Shrank WH, Rogstad TL, Parekh N. Waste in the US health care system: estimated costs and potential for savings. JAMA. 2019;322:1501-1509. doi:10.1001/jama.2019.13978

37. Antman E, Braunwald E. Managing stable ischemic heart disease. N Engl J Med 2020;382:1468-1470. doi: 10.1056/NEJMe2000239 
38. Makary MA, Daniel M. Medical error - the third leading cause of death in the US. BMJ 2016;353:i2139

39. Ofri D. Medical Errors During the Coronavirus Crisis. The New York Times. May 24, 2020.

https://www.nytimes.com/2020/05/22/opinion/sunday/coronavirus-medical-errors-hospitals.html. Accessed May 24, 2020.

40. Esposito L. Technology and Innovation Solutions Must Lead the Way to Covid-19 Recovery. The Conference Board Solutions Briefs 2020. https://www.ced.org/2020-solutions-briefs/technology-andinnovation-solutions-must-lead-the-way-to-Covid-19-recovery. Accessed May 17, 2020.

41. Pronovost P. A Dose of Systems Engineering to Close the Healthcare Chasms Exposed by Covid-19. LinkedIn post published May 25, 2020. https://www.linkedin.com/pulse/dose-systems-engineeringclose-healthcare-chasms-peter-pronovost/?trackingld=cDoHE4QRQqyqjHZIXDf\%2BPw\%3D\%3D. Accessed May 25, 2020.

42. Mims C. Not Even a Pandemic Can Slow Down These Technology Giants. The Wall St. Journal. May 23, 2020. https://www.wsj.com/articles/not-even-a-pandemic-can-slow-down-the-biggest-tech-giants11590206412. Accessed May 23, 2020.

43. Dafny L, McWilliams JM. Primary Care Is Hurting: Why Aren't Private Insurers Pitching In? Health Affairs Blog, May 21, 2020. https://www.healthaffairs.org/do/10.1377/hblog20200519.916904/full/. Accessed May 21, 2020.

44. Tobin-Tyler E, Ahmad B. Marrying Value-Based Payment and the Social Determinants of Health through Medicaid ACOs: Implications for Policy and Practice. Milbank Memorial Fund, May 2020. https://www.milbank.org/publications/marrying-value-based-payment-and-the-social-determinants-ofhealth-through-medicaid-acos-implications-for-policy-and-practice/. Accessed May 17, 2020.

45. Nash D. The Business Case for Social Determinants. Am Health Drug Benefits. 2019;12:387-388.

46. Orszag P, Rekhi R. The Economic Case for Vertical Integration in Health Care. April 15, 2020. https://catalyst.nejm.org/doi/abs/10.1056/CAT.20.0119. Accessed May 17, 2020.

47. National Association of ACOs. Survey Shows ACOs' Concerns About the Effect of COVID-19. https://www.naacos.com/survey-shows-acos--concerns-about-the-effect-of-covid-19. Accessed May 17, 2020. 
48. Atkinson R. V-E Day Forged a World Still Worth Defending. The Wall St. Journal. May 1, 2020. https://www.wsj.com/articles/v-e-day-forged-a-world-still-worth-defending-11588341627. Accessed May 1, 2020. 
Table 1. Results for Hospitals in Philadelphia County-April 2019 Discharges

\begin{tabular}{|l|c|c|c|}
\hline & $\begin{array}{c}\text { Total Number } \\
\text { of Discharges in } \\
\text { April 2019 }\end{array}$ & $\begin{array}{c}\text { Percent } \\
\text { Mortality }\end{array}$ & $\begin{array}{c}\text { Average } \\
\text { Length of } \\
\text { Stay }\end{array}$ \\
\hline Heart Attack - Angioplasty/Stent & 98 & $1.0 \%$ & 3.9 \\
\hline Heart Attack - Medical Management & 136 & $3.7 \%$ & 4.8 \\
\hline Chronic Obstructive Pulmonary Disease & 337 & $0.6 \%$ & 3.8 \\
\hline Diabetes - Medical Management & 364 & $0.3 \%$ & 4.0 \\
\hline Heart Failure & 787 & $1.4 \%$ & 5.8 \\
\hline Stroke & 330 & $3.6 \%$ & 5.1 \\
\hline
\end{tabular}


Table 2. April 2019 Ambulatory Surgery Claims with Cancer as the Principal Diagnosis

\begin{tabular}{|l|l|l|l|l|l|l|}
\hline & \multicolumn{2}{|l|}{ Hospital-Based } & \multicolumn{2}{l}{ Freestanding } \\
\cline { 2 - 7 } & $\begin{array}{l}\text { Total } \\
\text { Number of } \\
\text { Ambulatory } \\
\text { Surgery } \\
\text { Claims in } \\
\text { April 2019 } \\
\text { Patients } \\
\text { Age 60 } \\
\text { and } \\
\text { Older }\end{array}$ & $\begin{array}{l}\text { \% of } \\
\text { Patients } \\
\text { Age 85 } \\
\text { and } \\
\text { Older }\end{array}$ & $\begin{array}{l}\text { Ondal } \\
\text { Number of } \\
\text { Ambulatory } \\
\text { Surgery } \\
\text { Claims in } \\
\text { April 2019 }\end{array}$ & $\begin{array}{l}\text { \% of } \\
\text { Patients } \\
\text { Age 60 } \\
\text { and } \\
\text { Older }\end{array}$ & $\begin{array}{l}\text { \% of } \\
\text { Patients } \\
\text { Age 85 } \\
\text { and } \\
\text { Older }\end{array}$ \\
\hline $\begin{array}{l}\text { Pennsylvania } \\
\text { Statewide (all } \\
\text { counties) }\end{array}$ & 25,477 & $67.9 \%$ & $4.6 \%$ & 2,074 & $77.6 \%$ & $11.8 \%$ \\
\hline Bucks County & 218 & $68.8 \%$ & $8.3 \%$ & 21 & $61.9 \%$ & $14.3 \%$ \\
\hline Chester County & 938 & $69.2 \%$ & $6.5 \%$ & 54 & $74.1 \%$ & $7.4 \%$ \\
\hline Delaware County & 236 & $69.5 \%$ & $5.1 \%$ & 132 & $80.3 \%$ & $9.1 \%$ \\
\hline Montgomery County & 596 & $70.5 \%$ & $7.4 \%$ & 100 & $73.0 \%$ & $11.0 \%$ \\
\hline Philadelphia County & 10,345 & $66.3 \%$ & $2.6 \%$ & 130 & $67.7 \%$ & $5.4 \%$ \\
\hline
\end{tabular}


Table 3. Jefferson Health Utilization Data

\begin{tabular}{|l|c|c|c|}
\hline \multicolumn{1}{|c|}{ Utilization } & April 2019 & April 2020 & \% Change in 2020 \\
\hline Emergency Room Visits & 41,850 & 15,103 & $-63.9 \%$ \\
\hline Outpatient Visits & 134,979 & 25,986 & $-80.7 \%$ \\
\hline $\begin{array}{l}\text { Radiology Tests } \\
\text { (all kinds) }\end{array}$ & 170,000 & 42,500 & $-75 \%$ \\
\hline $\begin{array}{l}\text { Myocardial Infarction } \\
\text { and Stroke (acute } \\
\text { facility discharges) }\end{array}$ & 248 & 157 & $-36.7 \%$ \\
\hline
\end{tabular}

